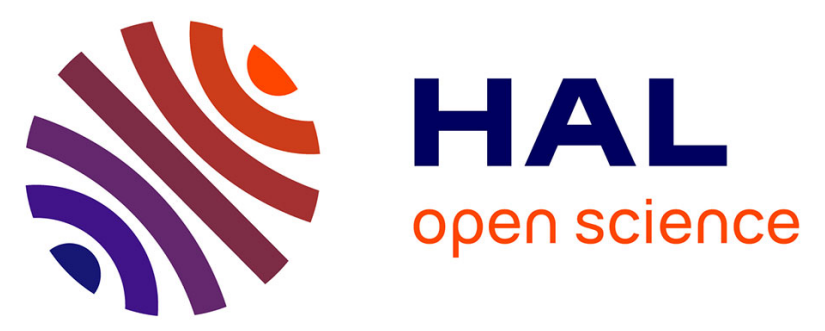

\title{
Thermal Conductivity of FeS and Its Implications for Mercury's Long-Sustaining Magnetic Field
}

Geeth Manthilake, J. Chantel, J. Monteux, Denis Andrault, Mohamed Ali M.A. Bouhifd, Nathalie Bolfan-Casanova, E. Boulard, N. Guignot, A. King, J. Itié

\section{To cite this version:}

Geeth Manthilake, J. Chantel, J. Monteux, Denis Andrault, Mohamed Ali M.A. Bouhifd, et al.. Thermal Conductivity of FeS and Its Implications for Mercury's Long-Sustaining Magnetic Field. Journal of Geophysical Research. Planets, 2019, 124 (9), pp.2359 - 2368. 10.1029/2019JE005979 . hal-02284266

\section{HAL Id: hal-02284266 \\ https://hal.uca.fr/hal-02284266}

Submitted on 13 Nov 2020

HAL is a multi-disciplinary open access archive for the deposit and dissemination of scientific research documents, whether they are published or not. The documents may come from teaching and research institutions in France or abroad, or from public or private research centers.
L'archive ouverte pluridisciplinaire HAL, est destinée au dépôt et à la diffusion de documents scientifiques de niveau recherche, publiés ou non, émanant des établissements d'enseignement et de recherche français ou étrangers, des laboratoires publics ou privés.

$$
\text { Copyright }
$$


Manthilake Geeth (Orcid ID: 0000-0001-8161-081X)

Monteux Julien (Orcid ID: 0000-0002-1059-6165)

Boulard Eglantine (Orcid ID: 0000-0003-2865-6098)

Thermal conductivity of FeS and its implications for Mercury's long sustaining magnetic field

G. Manthilake ${ }^{1 *}$, J. Chantel $^{2}$, J. Monteux ${ }^{1}$, D. Andrault ${ }^{1}$, M.A. Bouhifd ${ }^{1}$, N. Bolfan

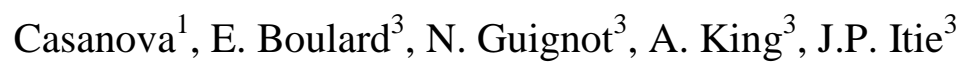

Laboratoire Magmas et Volcans, Université Clermont Auvergne, CNRS, IRD, OPGC, 63000 Clermont-Ferrand, France.

2. Unite Matériaux et Transformations, CNRS, Université de Lille, 59655 Villeneuve d'Ascq, France.

Synchrotron SOLEIL, 91192 Gif-sur-Yvette, France.

*Corresponding author: G. Manthilake (geeth.manthilake@uca.fr)

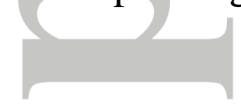

\section{Key points}

- Incorporation of S significantly reduces both electrical and thermal conductivities of FeS.

- The low thermal conductivity of FeS may have prevented the Mercurian core from rapid solidification.

- Mercury dynamo can be driven by both thermal and chemical buoyancy forces.

This article has been accepted for publication and undergone full peer review but has not been through the copyediting, typesetting, pagination and proofreading process which may lead to differences between this version and the Version of Record. Please cite this article as doi: 10.1029/2019JE005979 


\section{Abstract}

The MESSENGER mission revealed that Mercury's magnetic field might have operated since 3.7-3.9 Ga. While the intrinsic magnetism suggests an active dynamo within Mercury's core, mechanism that is responsible for sustaining the dynamo for prolonged period of time remains unknown. Here we investigate the electrical conductivities of $\mathrm{Fe}-\mathrm{S}$ alloys at pressure of $8 \mathrm{GPa}$ and temperatures up to $1700 \mathrm{~K}$. We show that the electrical conductivity of Fe-S alloys at $1500 \mathrm{~K}$ is about $10^{3} \mathrm{~S} / \mathrm{m}$, two orders of magnitude lower than the previously assumed value for dynamo calculations. The thermal conductivity was estimated using the Wiedemann-Franz law. The total thermal conductivity of $\mathrm{FeS}$ is estimated to be $\sim 4 \mathrm{Wm}^{-1} \mathrm{~K}^{-1}$ at the Mercurian coremantle boundary conditions. The low thermal conductivity suggests that a thermally driven dynamo operating on Mercury is more likely than expected. If coupled with chemical buoyancy sources, it is possible to sustain an intrinsic dynamo during timescales compatible with the MESSENGER observations.

\section{Plain language summary}

Mercury's weak magnetic field intensity that persisted over the last 3.9 billion years has long baffled the planetary science community. Various explanations have been proposed; nevertheless, there has been no consensus on how the intrinsic dynamo with such weak energetics exists in Mercury for prolonged period. In our submitted manuscript, we exclusively looked at the electrical and thermal conductivity in $\mathrm{Fe}-\mathrm{S}$ alloys, the dominant phase in Planet Mercury's outer core. Our results indicate that electrical conductivity of Fe-S alloys is two orders of magnitude lower than the previously assumed value for dynamo calculations. The low thermal conductivity obtained in this study suggests that the heat extraction from Mercury's core through the solid Fe-S layer is a highly inefficient process. Our estimations suggest the heat-flux from the core only produces less than 1 TW of energy. The low heat flux prevents the Mercurian core from rapid solidification, sustaining an intrinsic dynamo in Mercury since $\sim 3.9 \mathrm{Ga}$. 


\section{Introduction}

The planet Mercury currently exhibits a surface magnetic field with a field strength representing $1.1 \%$ that of the Earth's magnetic field (Anderson et al., 2011). The spin-aligned axisymmetric and offset dipole-dominated field is considered unique among planetary magnetic fields (Tian, Zuber, \& Stanley, 2015). The low-altitude magnetic field measurements by the MESSENGER mission have revealed a remnant magnetization in Mercury's crust with age of magnetization in the range of 3.7-3.9 Ga (Johnson et al., 2015). The presence of a magnetic field in the early in Mercury's history as early as $3.9 \mathrm{Ga}$ and the extremely weak magnetic field strengths in present day Mercury may suggest that Mercury's magnetic field may have been active for the last 3.7-3.9 Ga. While the observed intrinsic magnetism suggests an active dynamo generated in Mercury's liquid outer core, how Mercury's magnetic field sustained for a prolonged period of time remains puzzling even in the light of our current understanding of the Earth and planetary dynamos (Johnson et al., 2015).

It has been suggested that Mercury's dynamo is currently generated by chemical convection (Breuer, Rueckriemen, \& Spohn, 2015; Cao et al., 2014; Chen, Li, \& Hauck, 2008; Dumberry \& Rivoldini, 2015). The low magnetic field intensity of planet Mercury has been discussed using thermoelectric (D. J. Stevenson, 1987), thin shell (Stanley, Bloxham, Hutchison, \& Zuber, 2005), thick shell (Heimpel, Aurnou, Al-Shamali, \& Gomez Perez, 2005) and feedback (Glassmeier, Auster, \& Motschmann, 2007) dynamo models. Recent dynamo studies linked the low intensity and the axisymmetry of the magnetic field to a stably stratified layer with latitudinal heat-flux variations (Ulrich R. Christensen \& Wicht, 2008; Ulrich R Christensen, 2006; Schubert, Chan, Liao, \& Zhang, 2004; Tian et al., 2015).

The chemical composition and the internal structure of Mercury remain poorly understood mainly due to the lack of observational constraints (Margot, Hauck, Mazarico, 
Padovan, \& Peale, 2018). Mercury's solid outer shell overlying the liquid core is estimated to be $\sim 400 \mathrm{~km}$ thick and believed to consist mainly of silicate minerals (Hauck et al., 2013; Rivoldini \& Van Hoolst, 2013). Recent gravity field analyses indicate that Mercury's internal structure consists of an Fe-S-Si liquid outer core (Chabot, Wollack, Klima, \& Minitti, 2014; Hauck et al., 2013; Knibbe \& van Westrenen, 2015; Margot et al., 2018; Rivoldini \& Van Hoolst, 2013; D. E. Smith et al., 2012). A substantial number of studies have considered S and $\mathrm{Si}$ as principal alloying element in the liquid outer core (Chabot et al., 2014; Hauck et al., 2013; Malavergne, Toplis, Berthet, \& Jones, 2010; Namur, Charlier, Holtz, Cartier, \& McCammon, 2016; Rivoldini, Van Hoolst, \& Verhoeven, 2009; Schubert, Ross, Stevenson, \& Spohn, 1988; David J. Stevenson, Spohn, \& Schubert, 1983). The presence of an inner core in Mercury has been debated (Margot et al., 2018). The Mercury interior models also suggest the presence of a solid inner core, which may have formed as a result of planetary cooling (Veasey \& Dumberry, 2011). Recent estimations indicate that the diameter of the solid inner core would be 0.3-0.7 of the diameter of Mercury's core (Genova et al., 2019) .

The elemental composition analyses during the MESSENGER mission indicate 1-4 wt. \% of Fe and $\mathrm{S}$ in Mercury's surface (Evans et al., 2012; Nittler et al., 2011). The high S abundance in the Mercury's mantle and coupled with low surface abundance of Fe suggests Mercury may have formed from highly reduced CB chondrites (Namur et al., 2016). The recent based on $\mathrm{S}$ solubility in reduced mafic silicate melts suggest 7-11 wt.\% $\mathrm{S}$ in the mantle and $<1.5$ wt.5 S in the metallic inner core for a bulk S contents of 4 wt. \% in Mercury (Namur et al., 2016). Similarly, metal-silicate partitioning experiments indicate that decrease of S contents in the core when Si contents increases (Chabot et al., 2014). These experimental results indicate that Mercury's core must contain Si if the S contents in the core is $<20$ wt.\%. If Si contents in the core would be > $10 \mathrm{wt} . \%$, the $\mathrm{S}$ contents in the core should be $<2 \mathrm{wt} . \%$ (Chabot et al., 2014). 
The unusual feature in Mercury's internal structure models is the possibility of a solid FeS layer at the core-mantle boundary (D. E. Smith et al., 2012). The higher bulk density observed for Mercury's outer shell appears to be compatible with a silicate mantle with FeS layer with a thickness of $\sim 90 \mathrm{~km}$ (Hauck et al., 2013; Namur et al., 2016). The immiscibility of $\mathrm{Fe}-\mathrm{S}$ and $\mathrm{Fe}-\mathrm{Si}$ liquids in the Fe-S-Si ternary system would result segregation of $\mathrm{Fe}-\mathrm{S}$ liquids from Fe-S-Si ternary system when the pressure is below $15 \mathrm{GPa}$ (Morard \& Katsura, 2010; Sanloup \& Fei, 2004). The S contents up to 4 wt.\% in silicate appear to fall within the liquid- liquid immiscibility field of Fe-S-Si system at the Mercury core mantle boundary (CMB) pressure (Chabot et al., 2014; Namur et al., 2016). The origin of a FeS layer can be explained by the crystallization of $\mathrm{FeS}$ in binary $\mathrm{Fe}-\mathrm{FeS}$ system from the segregated $\mathrm{S}$ rich Fe liquids (Fei, Bertka, \& Finger, 1997; Hauck et al., 2013). Due to the density contrast in solid $\mathrm{FeS}$ in Fe-S-Si liquid, the crystalized $\mathrm{FeS}$ is expected to float, forming a stable layer beneath the silicate mantle (Hauck et al., 2013). The possibility of a liquid FeS rich layer overlying Fe-S-Si core has also been discussed in a recent study (Pommier, Leinenweber, \& Tran, 2019). In this model, an insulating liquid FeS layer with the thickness $>40 \mathrm{~km}$ is expected to control the heat-flow from the core influencing the generation and the sustainability of mercury's magnetic field (Pommier et al., 2019).

While a solid FeS layer at the CMB has been an important feature in Mercury's interior models, a number of recent studies have supported the low $\mathrm{S}$ contents or $\mathrm{S}$ absent conditions in Mercury's core, thereby questioning the stability of FeS later at the CMB (Chabot et al., 2014; Genova et al., 2019; Knibbe \& van Westrenen, 2018; Margot et al., 2018). The silicate-metal partitioning experiments (Chabot et al., 2014) suggest S-free conditions, if the Si contents exceeds 25 wt.\% in the Mercury's core. However, such extreme partitioning of Si into the core would alter the major element ratios in the silicate mantle. Recent study investigating the density of FeS and S rich liquids (Knibbe \& van Westrenen, 
2015) reported higher density for FeS compared to the residual liquids, requiring a separate mechanism to stabilize a FeS layer at the base of Mercury's mantle. The recent geodetic constrains indicate a slightly higher value for gravitational potential Love number than previous estimations, supporting for a warm and weak mantle rather than rigid FeS late at Mercury's CMB (Genova et al., 2019).

The presence of solidified FeS layer the boundary between Mercury's liquid outer core and solid silicate mantle is assumed, this could have significant implications for the core dynamics. It has been suggested that the weak magnetic field strength observed for Mercury can be explained by the presence of conductive layer overlying the convective liquid outercore (Ulrich R Christensen, 2006). Due to the stratification of the liquid core, the convection driven dynamo operates only at deep part of the liquid core and the dynamo field may diffuses through the overlying conductive layers producing weak magnetic field strengths (Ulrich R Christensen, 2006). The heat flow across the CMB controls the solidification of the liquid core and the buoyancy sources available to generate a planetary dynamo (B. Buffett, 2003). The electrical and thermal conductivities of Fe-S compounds are therefore key physical properties to understand Mercury's core dynamics. In this study, we investigate the electrical and thermal conductivities of Fe-S alloys at high pressure and temperature, the principal constituent of Mercury's core-mantle boundary, with the aim of understanding the influence of Fe-S layer on the heat extraction from Mercury's core. We discuss how the outer core composition evolution influences the heat extraction from the core of Mercury and favor an intrinsic dynamo driven by thermal and chemical buoyancy forces and sustained for a prolonged period.

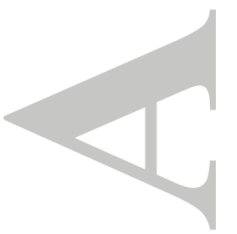




\section{Methods}

Three different $\mathrm{FeS}_{\mathrm{x}}$ samples with varying sulfur contents (x, in mol) 0.01, 0.02 and 0.05 were prepared mixing reagent grade $\mathrm{Fe}$ and $\mathrm{S}$ powders. For the $\mathrm{FeS}(\mathrm{x}=0.5)$ composition we used commercially available reagent grade $\mathrm{FeS}$ power. The powder mixtures were compressed to desired pressure and kept at $1000 \mathrm{~K}$ for more than 1 hours to obtain solid cylindrical samples for electrical conductivity measurements in multi-anvil apparatus. The high-pressure and high-temperature experiments were conducted at $8 \mathrm{GPa}$ up to $1700 \mathrm{~K}$ using the 1200-ton DIA-type multi-anvil module at the PSICHE beamline in SOLEIL Synchrotron (France). Additional off-line experiments were performed using 1500-ton multi-anvil press at the Laboratoire Magmas et Volcans, France. For high-pressure generation, we used an octahedral $\mathrm{MgO}+\mathrm{Cr}_{2} \mathrm{O}_{3}$ pressure medium in a $10 / 4$ multi-anvil configuration. In order to electrically insulate the sample from the Re furnace during the measurements of electrical conductivity, we placed the polycrystalline Fe-S samples within a $\mathrm{MgO}$ capsule. The two iron (Fe) discs placed on the top and at the bottom of the cylindrical Fe-S sample served as electrodes for electrical conductivity measurements. Sample temperature was monitored using a tungsten-rhenium $\left(\mathrm{W}_{95} \mathrm{Re}_{5}-\mathrm{W}_{74} \mathrm{Re}_{26}\right)$ thermocouple junction located at one end of the sample (Fig. 1).

Energy-dispersive x-ray diffraction using a CAESAR-type diffractometer (Wang et al., 2004) was used to determine the sample pressure and verify the sample state. We use the pressure-volume-temperature equation of state of $\mathrm{MgO}$ to determine the sample pressure and the accuracy of pressure determination is estimated to be $\sim 0.5 \mathrm{GPa}$. Diffraction peaks corresponding to Fe-S alloys are clearly visible in solid samples and the melting of $\mathrm{Fe}-\mathrm{S}$ is characterized by a broad band of diffuse scattering as described previously elsewhere (Andrault et al., 2018). We also acquired radiographic images of the sample to determine the sample lengths, which were crucial for the accurate determination of electrical conductivity at 
each temperature. The focused beam configuration used in these experiments has the advantage to produce almost flat field corrected images, a feature usually not available when using multi-anvil modules (Andrault et al., 2018).

The electrical conductivity measurements were performed using the Kelvin resistance measurement technique (e.g. Deng, Seagle, Fei, \& Shahar, 2013). In this method, the digital multi-meter measured the current going through the subject and the voltage drop across it, eliminating the lead and contact resistance from the measurement (Fig 1). This is an advantage for precise measurement of sample with low resistance values such as metals. The electrical conductivity at each temperature can be calculated using the sample dimensions obtained using the $\mathrm{X}$ ray radiograph using, $\sigma=l / R A$ where $\sigma$ is the electrical conductivity, $l$ is the sample length, $R$ is the measured sample resistance and $A$ is the area of the cylindrical cross section. The temperature dependence of the electrical conductivity $\sigma$ can be described by the Arrhenius equation: $\sigma=\sigma_{0} e^{-\Delta H / k T}$, where $\sigma_{0}$ is the pre-exponential factor, $\Delta H$ is the activation enthalpy in $\mathrm{eV}, k$ is the Boltzmann constant in $\mathrm{eV} / \mathrm{K}$, and $T$ is absolute temperature in $\mathrm{K}$.

Thermal conductivity of Fe-S alloys was estimated using the Wiedemann-Franz law $\kappa=L_{0} \sigma T$, an empirical law expressing the thermal conductivity $(k)$ as a function of the electrical conductivity of a metal $(\sigma)$ and the temperature $(T)$ through a proportionality constant Lorenz ratio (L). The Lorenz ratio approaches the Sommerfeld derivation $L_{0}$, $2.44 \times 10^{-8} \mathrm{WK}^{-2}$ provided the thermal conductivity is purely electronic, the electron gas is highly degenerate and the relaxation time is same for electrical and thermal conduction (Klemens, 1989). The deviation of the Lorenz ratio has been observed for Fe alloys (de Koker, Steinle-Neumann, \& Vlcek, 2012; Secco, 2017). In metallic alloys such as Fe-S, the thermal transport is a complex process due to the coexistence of electron and phonon conduction. The total thermal conductivity $\left(\kappa_{t o t}\right)$ is the sum of its electronic component $\left(\kappa_{e}\right)$, 
and its phononic component $\left(\kappa_{p h}\right)$. In high purity metals, the electronic component dominates the thermal conduction, however, in metallic alloys the heat conduction through phonon vibration becomes significant (Klemens \& Williams, 1986; Konôpková, McWilliams, Gómez-Pérez, \& Goncharov, 2016).

\section{Results}

Our findings show that the electrical conductivity of Fe-S compounds decreases with increasing temperature characteristic to the electrical conduction in metals and metal alloys (Fig. 2a). We observe that even a minor increase of sulfur contents reduces the electrical conductivity of Fe-S alloys (Fig.2a). At $1000 \mathrm{~K}$, the incorporation of $0.01 \mathrm{~mol}$ of $\mathrm{S}$ in $\mathrm{Fe}-\mathrm{S}$ alloys decreases the electrical conductivity by two orders of magnitude to $10^{4} \mathrm{~S} / \mathrm{m}$ compared to pure $\mathrm{Fe}\left(10^{6} \mathrm{~S} / \mathrm{m}\right)$ (Powell, 1939). The electrical conductivity of $\mathrm{FeS}$, corresponding to the sulfur content expected at the solid layer at the Mercury's core-mantle boundary is expected to be about $10^{2} \mathrm{~S} / \mathrm{m}$ at $1700 \mathrm{~K}$. This value is about three orders of magnitude smaller than the value of $10^{5} \mathrm{~S} / \mathrm{m}$ used in previous dynamo models (D. J. Stevenson, 2003). A change in activation enthalpy on melting of FeS (Fig. 2b) suggests the change of conduction mechanism from electronic conduction in a solid to electrolytic conduction in Fes melt.

The melting of FeS is confirmed by the disappearance of peaks above $1500 \mathrm{~K}$ (Fig. 3), consistent with experimentally derived Fe-S phase relations (Urakawa et al., 2004). The electrical conductivity of molten $\mathrm{FeS}$ is about $10^{2} \mathrm{~S} / \mathrm{m}$ at $1700 \mathrm{~K}$ and remains relatively unchanged with increasing temperature.

Our measured electrical conductivity of Fe-S compositions at $8 \mathrm{GPa}$ indicate significant lower values compared to the previously reported values for Fe-S alloys (Pommier, 2018) (Fig. 4). While we could not determine the exact cause of the discrepancy among different laboratory measurements, it's possible that the high conductivity may be 
originated from the presence of impurities in $\mathrm{Fe}-\mathrm{S}$ alloys For example, the experiments conducted on $\mathrm{Al}$ and $\mathrm{Sr}$ doped $\mathrm{FeS}_{2}$ (Osuwa \& Nwaokeorie, 2014) indicate $0.02 \mathrm{M}$ concentration of $\mathrm{Al}$ And $\mathrm{Sr}$ would increase the electrical conductivity of $\mathrm{FeS}_{2}$ by more than factor 10. However, calculations based on first-principles electronic band structure calculation of hcp Fe-based alloys at $40 \mathrm{GPa}$ (Gomi \& Yoshino, 2018) indicate Si impurity concentrations up to 30 at. $\%$ is required to decrease the electrical conductivity by factor 100 . Another possibility for high electrical conductivity could be the partial reaction of Fe and S to form Fe-S alloy with high Fe contents.

\section{Discussion}

In metallic alloys, the electrical conduction is controlled solely by the movements of electrons, while heat is carried by both electron vibrations and phonon collisions (Klemens \& Williams, 1986). It is generally assumed that the phonon (lattice) thermal conductivity is negligible in metals and the electronic component is determined via the Sommerfeld value of the Lorentz ratio $\left(L_{0}\right)$. The estimated electronic component of thermal conductivity varies from $0.5 \mathrm{Wm}^{-1} \mathrm{~K}^{-1}$ for $\mathrm{FeS}_{0.01}$ to $0.006 \mathrm{Wm}^{-1} \mathrm{~K}^{-1}$ for $\mathrm{FeS}$ at $1300 \mathrm{~K}$ (Fig. 5). These values represents the lower bound of the thermal conductivity for Fe-S alloys (Pommier, 2018).

In metallic alloys however, scattering of electrons by solute atoms greatly reduces the electronic thermal conductivity, making heat transport via lattice vibrations a dominant factor (Klemens \& Williams, 1986). Thus for metallic alloys at high temperature, the thermal conductivity is described by the Smith-Palmer equation (C. S. Smith \& Palmer, 1935), $\kappa=L_{0} \sigma T+D$, an empirical relation linking thermal conductivity to electrical conductivity via a constant $D$, which describes the temperature dependent phonon thermal conductivity $\left(\kappa=L_{0} \sigma T+D T^{-a}\right)$. Due to strong solute scattering, the phonon thermal conductivity of alloys are expected to approach a constant value at high temperature (Klemens \& Williams, 
1986). For example, the lattice thermal conductivity Fe-Cr-Ni alloy systems converge into a narrow range of $4.6-6.0 \mathrm{~W} / \mathrm{m} \mathrm{K}$ at $1000 \mathrm{~K}$ (Klemens \& Williams, 1986).

The lattice thermal conductivity measurements of $\mathrm{Fe}-\mathrm{S}$ alloys were limited to $\mathrm{FeS}_{2}$ composition, which was reported at super-cooled conditions in the temperature range 50-300 $\mathrm{K}$ (Popov, Fedorov, \& Kuznetsov, 2013). The thermal conductivity of $\mathrm{FeS}_{2}$ at $300 \mathrm{~K}$ is estimated to be $42 \pm 1 \mathrm{Wm}^{-1} \mathrm{~K}^{-1}$. Extrapolation of this value to high temperature based on the theoretically predicted temperature dependence of phonon thermal conductivity of $T^{a}$ (Klemens \& Williams, 1986) indicates the thermal conductivity of $\mathrm{FeS}_{2}$ at $1300 \mathrm{~K}$ would be about $3.6 \mathrm{~W} / \mathrm{m} \mathrm{K}$. In order to estimate the total thermal conductivity of FeS (electronic + lattice), we have modeled the thermal conductivity of end member $\mathrm{Fe}-\mathrm{S}$ compositions together with data from the $\mathrm{FeS}_{2}$ system (Fig 4). The thermal conductivity of $\mathrm{Fe}$ was calculated from electrical conductivity data of (Powell, 1939) Thermal conductivity of S at $300 \mathrm{~K}$ was obtained from (Slack, 1965). By fitting of total thermal conductivity of Fe, $\mathrm{FeS}_{2}$ and $\mathrm{S}$ with power law relation, we obtain thermal conductivity $\sim 4 \mathrm{Wm}^{-1} \mathrm{~K}^{-1}$ for the $\mathrm{FeS}$ at 1300 K, (Fig. 5).

The temperature at the Mercury's core mantle boundary have been investigated in numerous previous studies (Grott, Breuer, \& Laneuville, 2011; Hauck et al., 2013; Tosi, Grott, Plesa, \& Breuer, 2013). The solidification of FeS below the CMB can be expected if the temperatures at the core mantle boundary decrease below $1700 \mathrm{~K}$ (Breuer et al., 2015). We have obtained the thermal conductivity at $1300 \mathrm{~K}$, close to the eutectic temperature of FeFeS system at $10 \mathrm{GPa}$ (Fei et al., 1997; Morard et al., 2007). Due to the weak temperature dependence of thermal conductivity at high temperature, a significant variation to the estimated phonon thermal conductivity could not be expected within 1200-1700 K temperature range. 
Based on our estimation of the thermal conductivity of $4 \mathrm{Wm}^{-1} \mathrm{~K}^{-1}$ assumed for FeS at $1300 \mathrm{~K}$, we have computed the Mercurian core heat flow for a range of thermal boundary layer (TBL) thicknesses and possible temperature gradients across the TBL (Hauck et al., 2013; Rivoldini et al., 2009; Tosi et al., 2013) (Fig. 6). It is worth noting that our estimated value for the Fe-S thermal conductivity at the $\mathrm{CMB}$ conditions is close to the mantle thermal conductivity value usually assumed for Mercury's mantle convection models (Breuer, Labrosse, \& Spohn, 2010; Tosi et al., 2013) meaning that the two reservoirs may be indistinct in terms of thermal conductivity. We have calculated the heat flow $Q$ based on the Fourier's law of thermal conduction:

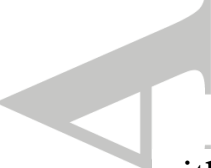

$$
Q=4 \pi R_{c}^{2} k_{t o t}(\Delta T / \delta)
$$

with $R_{c}$ the core radius (=2000 $\mathrm{km}$ for Mercury), $\Delta T$ the temperature difference across the thermal boundary layer and $\delta$ the boundary layer thickness. The estimated heat flows computed from our thermal conductivity model indicate that the energy evacuated by core heat flow is $\approx 10 \mathrm{TW}$ for a TBL with a thickness of $10 \mathrm{~km}$ and a temperature contrast of 500 $\mathrm{K}$ (Fig 4). The heat flow from the core is substantially reduced when increasing the TBL thickness, to $\approx 1 \mathrm{TW}$ for a $100 \mathrm{~km}$ thick TBL layer.

To drive a dynamo in a terrestrial planet, three conditions are necessary (e.g. Monteux, Jellinek, \& Johnson, 2011) (1) The metallic core has to convect meaning that the heat flow out of the core needs to overcome the adiabatic heat flow (David J. Stevenson et al., 1983), (2) The rate of gravitational potential energy released by convection has to be much larger than the rate of ohmic dissipation (B. A. Buffett, 2002) (3) The convective motions has to exhibit a complex structure to carry the magnetic field lines (leading to a critical magnetic Reynolds number) (U R Christensen \& Aubert, 2006). Fig. 6 shows that the heat flow inferred from our study is larger than the adiabatic heat flow for a wide range of temperature contrasts and thermal boundary thicknesses meaning that thermally driven dynamo is a likely 
process on Mercury. Low values for both thermal and electrical conductivities remain puzzling to explain Mercury's magnetic field. In the Earth's core, values of the thermal conductivity range between 90 and $150 \mathrm{~W} \mathrm{~m}^{-1} \mathrm{~K}^{-1}$ (de Koker et al., 2012; Pozzo, Davies, Gubbins, \& Alfè, 2012). Recent laboratory measurements suggested that the thermal conductivity of polycrystalline iron at Mercury's core conditions is $113-125 \mathrm{Wm}^{-1}{ }^{-1}$ (Deng et al., 2013). Large thermal conductivities increase the heat flux along the core adiabat and reduce the lifetime of a thermally driven dynamo (Breuer et al., 2015). The electrical conductivity of Fe-S at P/T conditions compatible with Mercury's core is about two orders of magnitude lower than for pure iron. To overcome a critical magnetic Reynolds number of 50 (Wicht et al., 2007), $20 \mathrm{~mm} / \mathrm{s}$ typical flow speed is required to maintain an active dynamo for Mercury, which is about 200 times stronger than that of the Earth's outer core. Moreover, if sulfur is the major light element in Mercury's core and if its weak magnetic field is related to a low electrical conductivity, our results would also suggest a very weak magnetic field for Ganymede, which contradicts Galileo magnetometer measurements (Kivelson et al., 1996).

It is worth noting that the heat flux from the core is controlled by the thermal evolution of the mantle. In the early history of Mercury, its core was likely to be liquid with Fe alloys (Fe-S, Fe-Si) (Fig. 7a). Consequently, the thermal conductivity of the core was large; the primitive heat was efficiently evacuated possibly enhanced by a surrounding partially molten silicate magma ocean. In this early regime, the dynamo was only thermally driven. Numerical models (Tosi et al., 2013) assuming a core thermal conductivity of $40 \mathrm{Wm}^{-}$ ${ }^{1} \mathrm{~K}^{-1}$ indicate that a thermally driven dynamo would be feasible during the first few hundred million years of the evolution of Mercury. The value of the thermal conductivity inferred from our study would reduce the adiabatic core heat flux threshold for thermally driven dynamo from $\approx 20 \mathrm{~mW} / \mathrm{m}^{2}$ (Tosi et al., 2013) to $\approx 3 \mathrm{~mW} / \mathrm{m}^{2}$. According to Tosi et al. (2013), such a low threshold heat flux value could be overcome during the last $\approx 2$ Gyr of Mercury's 
history. Our estimations (Fig.6) indicate that such heat-flux values can be achieved even with a presence of a thin $(<1 \mathrm{~km}) \mathrm{FeS}$ layer.

A low thermal conductivity within the core can enhance thermal convection by reducing the threshold for thermally driven dynamo. In the case of a vigorous and thermallydriven convection, a stratified outer core would be difficult to envision as well as a strong skin-effect attenuation (Ulrich R. Christensen, Holzwarth, \& Reiners, 2009). However, a low thermal conductivity of the core combined with an overlying solid mantle would also limit the heat evacuation and favor the formation of a stable layer below the CMB. For a thick FeS layer to form and to possibly affect the magnetic field of Mercury, a complementary process can be invoked such as the formation of FeS layer during the solidification of Mercury's core. The growth of the inner core leads to an increase of the $\mathrm{S}$ concentration in the outer core (Fig. 7b). However, for crystallization to progress, the energy barrier for the formation of the first nucleus need to be overcome (Huguet, Van Orman, Hauck, \& Willard, 2018). In the classical view, either a critical super cooling of the core of order of $1000 \mathrm{~K}$ or transportation of solid metallic seeds from the mantle to the core when core reached liquidus temperature, are possible mechanisms that may surpass the nucleation energy barrier. It has been proposed recently that such nucleation substrates can be present in the core during the early in the Planet's history, leading to a slower inner core growth with smaller buoyancy flux (Huguet et al., 2018).

As the Fe-S concentration increases, the thermal conductivity of the outer core should decrease (Pommier, 2018). The low thermal conductivity $\left(4 \mathrm{Wm}^{-1} \mathrm{~K}^{-1}\right)$ inferred from our experiments means that dynamo action in Fe-S liquid core can be driven by thermal convection. At present, the second source of buoyancy force is likely to be related to chemical processes driven by crystallization in the iron rich core (Breuer et al., 2015; Dumberry \& Rivoldini, 2015) but the low thermal conductivity of Fe-S means that the 
dynamo can be both thermally and chemically driven (Fig. 7c). The sum of these two processes may explain the longevity of the dynamo of Mercury. Moreover, by limiting the amount of heat flowing from the core, the solidification of the Fe-S layer may have prevented the Mercurian core (and potentially the Ganymede's core) from rapid solidification, sustaining an intrinsic dynamo by buoyancy forces in Mercury for timescales larger than 1Gyr compatible with the MESSENGER mission observations.

\section{Acknowledgements}

Discussions with David Stevenson and Ulrich R. Christensen help improved the manuscript. We thank the Editor Steven A. Hauck, II, A. Pommier and the unanimous reviewer for their constructive comments. G.M. acknowledges funding from the French PNP program (INSUCNRS). This research was financed by the French Government Laboratory of Excellence initiative $\mathrm{n}^{\circ} \mathrm{ANR}-10$-LABX-0006, the Région Auvergne and the European Regional Development Fund. This is ClerVolc contribution number xx. The authors confirm that the raw data supporting the findings of this study are available within the article (Figures 2, 3 and

$4)$.

$$
\text { . }
$$

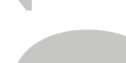

\section{References}

Anderson, B. J., Johnson, C. L., Korth, H., Purucker, M. E., Winslow, R. M., Slavin, J. A., ... Zurbuchen, T. H. (2011). The Global Magnetic Field of Mercury from MESSENGER Orbital Observations. Science, 333, 1859-1862. https://doi.org/10.1126/science.1211001

Andrault, D., Pesce, G., Manthilake, G., Monteux, J., Bolfan-Casanova, N., Chantel, J., ... Hennet, L. (2018). Deep and persistent melt layer in the Archaean mantle. Nature Geoscience, 11, 139-143. https://doi.org/10.1038/s41561-017-0053-9

Argyriades, D., Derge, G., \& Pound, G. M. (1959). Electrical Conductivity of Molten FeS. 
TRANSACTIONS OF THE METALLURGICAL SOCIETY OF AlME, 215(December), 909-912.

Breuer, D., Labrosse, S., \& Spohn, T. (2010). Thermal evolution and magnetic field generation in terrestrial planets and satellites. Space Science Reviews, 152(1-4), 449500. https://doi.org/10.1007/s11214-009-9587-5

Breuer, D., Rueckriemen, T., \& Spohn, T. (2015). Iron snow, crystal floats, and inner-core growth: modes of core solidification and implications for dynamos in terrestrial planets and moons. Progress in Earth and Planetary Science, 2, 39.

https://doi.org/10.1186/s40645-015-0069-y

Buffett, B. (2003). The thermal state of Earth's core. Science, 299, 1675-1677. https://doi.org/10.1126/science.1081518

Buffett, B. A. (2002). The Thermal State of Earth's Core.

Cao, H., Aurnou, J. M., Wicht, J., Dietrich, W., Soderlund, K. M., \& Russell, C. T. (2014). A dynamo explanation for Mercury' s anomalous magnetic field, (May). https://doi.org/10.1002/2014GL060196.Recent

Chabot, N. L., Wollack, E. A., Klima, R. L., \& Minitti, M. E. (2014). Experimental constraints on Mercury's core composition. Earth and Planetary Science Letters, 390, 199-208. https://doi.org/10.1016/j.epsl.2014.01.004

Chen, B., Li, J., \& Hauck, S. A. (2008). Non-ideal liquidus curve in the Fe-S system and Mercury's snowing core. Geophysical Research Letters, 35(7), 10-14. https://doi.org/10.1029/2008GL033311

Christensen, U R, \& Aubert, J. (2006). Scaling properties of convection-driven dynamos in rotating spherical shells and application to planetary magnetic fields. Geophysical Journal International, 166, 97-114. https://doi.org/10.1111/j.1365-246X.2006.03009.x Christensen, Ulrich R., Holzwarth, V., \& Reiners, A. (2009). Energy flux determines 
magnetic field strength of planets and stars. Nature, 457, 167-169.

https://doi.org/10.1038/nature07626

Christensen, Ulrich R., \& Wicht, J. (2008). Models of magnetic field generation in partly stable planetary cores: Applications to Mercury and Saturn. Icarus, 196(1), 16-34. https://doi.org/10.1016/j.icarus.2008.02.013

Christensen, Ulrich R. (2006). A deep dynamo generating Mercury’s magnetic field. Nature, 444(7122), 1056-1058. https://doi.org/10.1038/nature05342

de Koker, N., Steinle-Neumann, G., \& Vlcek, V. (2012). Electrical resistivity and thermal conductivity of liquid Fe alloys at high $\mathrm{P}$ and T, and heat flux in Earth's core.

Proceedings of the National Academy of Sciences, 109(11), 4070-4073. https://doi.org/10.1073/pnas.1111841109

Deng, L., Seagle, C., Fei, Y., \& Shahar, A. (2013). High pressure and temperature electrical resistivity of iron and implications for planetary cores. Geophysical Research Letters, 40, 33-37. https://doi.org/10.1029/2012GL054347

Dumberry, M., \& Rivoldini, A. (2015). Mercury's inner core size and core-crystallization regime. Icarus, 248, 254-268.

https://doi.org/https://doi.org/10.1016/j.icarus.2014.10.038

Evans, L. G., Peplowski, P. N., Rhodes, E. A., Lawrence, D. J., McCoy, T. J., Nittler, L. R., Goldsten, J. O. (2012). Major-element abundances on the surface of mercury: Results from the messenger gamma-ray spectrometer. Journal of Geophysical Research E: Planets, 117(11), E00L07. https://doi.org/10.1029/2012JE004178

Fei, Y., Bertka, C. M., \& Finger, L. W. (1997). High-pressure iron-sulfur compound Fe3S2, and melting relations in the system Fe-FeS. Science, 275, 1621-1623.

Genova, A., Goossens, S., Mazarico, E., Lemoine, F. G., Neumann, G. A., Kuang, W., ... Zuber, M. T. (2019). Geodetic Evidence That Mercury Has A Solid Inner Core. 
Geophysical Research Letters, 46(7), 3625-3633.

https://doi.org/10.1029/2018GL081135

Glassmeier, K. H., Auster, H. U., \& Motschmann, U. (2007). A feedback dynamo generating Mercury's magnetic field. Geophysical Research Letters, 34(22), 1-5.

https://doi.org/10.1029/2007GL031662

Gomi, H., \& Yoshino, T. (2018). Impurity Resistivity of fcc and hcp Fe-Based Alloys : Thermal Stratification at the Top of the Core of Super-Earths. Frontiers in Earth Sciences, 6(217), 1-22. https://doi.org/10.3389/feart.2018.00217

Grott, M., Breuer, D., \& Laneuville, M. (2011). Thermo-chemical evolution and global contraction of mercury. Earth and Planetary Science Letters, 307(1-2), 135-146. https://doi.org/10.1016/j.eps1.2011.04.040

Hauck, S. A., Margot, J. L., Solomon, S. C., Phillips, R. J., Johnson, C. L., Lemoine, F. G., ... Zuber, M. T. (2013). The curious case of Mercury's internal structure. Journal of Geophysical Research E: Planets, 118(6), 1204-1220. https://doi.org/10.1002/jgre.20091

Heimpel, M. H., Aurnou, J. M., Al-Shamali, F. M., \& Gomez Perez, N. (2005). A numerical study of dynamo action as a function of spherical shell geometry. Earth and Planetary Science Letters, 236(1-2), 542-557. https://doi.org/10.1016/j.eps1.2005.04.032

Huguet, L., Van Orman, J. A., Hauck, S. A., \& Willard, M. A. (2018). Earth's inner core nucleation paradox. Earth and Planetary Science Letters, 487, 9-20. https://doi.org/10.1016/j.eps1.2018.01.018

Johnson, C. L., Phillips, R. J., Purucker, M. E., Anderson, B. J., Byrne, P. K., Denevi, B. W., Solomon, S. C. (2015). Low-altitude magnetic field measurements by MESSENGER reveal Mercury's ancient crustal field. Science, 348, 892-895.

https://doi.org/10.1126/science.aaa8720 
Kivelson, M. ., Khurana, K. ., Russell, C. T., Walker, R. ., Warnecke, J., Coroniti, F. ., ... Schubert, G. (1996). Discovery of Ganymede's magnetic field by the Galileo spacecraft. Nature, 384, 537-541.

Klemens, P. G. (1989). Theory of Lorenz Ratio of Metals and Alloys. In D. P. H. Hasselman \& J. R. Thomas (Eds.), Thermal Conductivity 20 (pp. 63-69). Boston, MA: Springer US. https://doi.org/10.1007/978-1-4613-0761-7_6

Klemens, P. G., \& Williams, R. K. (1986). Thermal conductivity of metals and alloys. International Materials Reviews, 31(5), 197-215. https://doi.org/10.1179/095066086790324294

Knibbe, J. ,, \& van Westrenen, W. (2015). The interior configuration of planet Mercury constrained by moment of inertia and planetary contraction. Journal of Geophysical Research Planets, 120, 1904-1923. https://doi.org/10.1002/2015JD023618.Received

Knibbe, J. ., \& van Westrenen, W. (2018). The thermal evolution of Mercury's Fe-Si core. Earth and Planetary Science Letters, 482, 147-159. https://doi.org/10.1016/j.epsl.2017.11.006

Konôpková, Z., McWilliams, R. S., Gómez-Pérez, N., \& Goncharov, A. F. (2016). Direct measurement of thermal conductivity in solid iron at planetary core conditions. Nature, 534, 99-101. https://doi.org/10.1038/nature18009

Malavergne, V., Toplis, M. J., Berthet, S., \& Jones, J. (2010). Highly reducing conditions during core formation on Mercury: Implications for internal structure and the origin of a magnetic field. Icarus, 206(1), 199-209. https://doi.org/10.1016/j.icarus.2009.09.001

Margot, J.-L., Hauck, S. A., Mazarico, E., Padovan, S., \& Peale, S. J. (2018). Mercury’s Internal Structure. In S. C. Solomon, B. J. Anderson, \& L. . Nittler (Eds.), Mercury - The view after MESSENGER. Cambridge University Press. Retrieved from http://arxiv.org/abs/1806.02024 
Monteux, J., Jellinek, A. M., \& Johnson, C. L. (2011). Why might planets and moons have early dynamos? Earth and Planetary Science Letters, 310(3-4), 349-359.

https://doi.org/10.1016/j.eps1.2011.08.014

Morard, G., \& Katsura, T. (2010). Pressure-temperature cartography of Fe-S-Si immiscible system. Geochimica et Cosmochimica Acta, 74(12), 3659-3667.

https://doi.org/10.1016/j.gca.2010.03.025

Morard, G., Sanloup, C., Fiquet, G., Mezouar, M., Rey, N., Poloni, R., \& Beck, P. (2007). Structure of eutectic Fe-FeS melts to pressures up to $17 \mathrm{GPa}$ : Implications for planetary cores. Earth and Planetary Science Letters, 263(1-2), 128-139.

https://doi.org/10.1016/j.eps1.2007.09.009

Namur, O., Charlier, B., Holtz, F., Cartier, C., \& McCammon, C. (2016). Sulfur solubility in reduced mafic silicate melts: Implications for the speciation and distribution of sulfur on Mercury. Earth and Planetary Science Letters, 448, 102-114.

https://doi.org/10.1016/j.eps1.2016.05.024

Nittler, L. R., Starr, R. D., Weider, S. Z., McCoy, T. J., Boynton, W. V., Ebel, D. S., ... Sprague, A. L. (2011). The major-element composition of Mercury's surface from MESSENGER X-ray spectrometry. Science, 333(6051), 1847-1850. https://doi.org/10.1126/science.1211567

Osuwa, J. C., \& Nwaokeorie, S. E. (2014). Analysis of Structural and Electrical Properties of Iron Sulfide (FeS2)Thin Films doped with Aluminum and Strontium impurities. IOSR Journal of Applied Physics, 6(6), 42-46. https://doi.org/10.9790/4861-06624246

Pommier, A. (2018). Influence of sulfur on the electrical resistivity of a crystallizing core in small terrestrial bodies. Earth and Planetary Science Letters, 496, 37-46.

https://doi.org/10.1016/j.epsl.2018.05.032

Pommier, A., Leinenweber, K., \& Tran, T. (2019). Mercury's thermal evolution controlled 
by an insulating liquid outermost core? Earth and Planetary Science Letters, 517, 125134. https://doi.org/10.1016/j.epsl.2019.04.022

Popov, P. A., Fedorov, P. P., \& Kuznetsov, S. V. (2013). Thermal conductivity of FeS2 pyrite crystals in the temperature range 50-300 K. Crystallography Reports, 58(2), 319321. https://doi.org/10.1134/s1063774513020223

Powell, R. W. (1939). Further measurements of the thermal and electrical conductivity of iron at high temperature. Proc. Phys. Soc., 51, 407-418.

Pozzo, M., Davies, C., Gubbins, D., \& Alfè, D. (2012). Thermal and electrical conductivity of iron at Earth's core conditions. Nature, 485, 355-358.

https://doi.org/10.1016/j.eps1.2014.02.047

Rivoldini, A., \& Van Hoolst, T. (2013). The interior structure of Mercury constrained by the low-degree gravity field and the rotation of Mercury. Earth and Planetary Science Letters, 377-378, 62-72. https://doi.org/10.1016/j.eps1.2013.07.021

Rivoldini, A., Van Hoolst, T., \& Verhoeven, O. (2009). The interior structure of Mercury and its core sulfur content. Icarus, 201(1), 12-30.

https://doi.org/10.1016/j.icarus.2008.12.020

Sanloup, C., \& Fei, Y. (2004). Closure of the Fe-S-Si liquid miscibility gap at high pressure. Physics of the Earth and Planetary Interiors, 147(1), 57-65.

https://doi.org/10.1016/j.pepi.2004.06.008

Schubert, G., Chan, K. H., Liao, X., \& Zhang, K. (2004). Planetary dynamos: Effects of electrically conducting flows overlying turbulent regions of magnetic field generation. Icarus, 172(2), 305-315. https://doi.org/10.1016/j.icarus.2004.06.007

Schubert, G., Ross, M. ., Stevenson, D. J., \& Spohn, T. (1988). Mercury’s thermal history and the generation of its magnetic field. In F. Vilas, C. R. Chapman, \& M. . Matthews (Eds.), Mercury (pp. 429-460). Tucson: The University of Arizona Press. 
Secco, R. A. (2017). Thermal conductivity and Seebeck coefficient of Fe and Fe-Si alloys: Implications for variable Lorenz number. Physics of the Earth and Planetary Interiors, 265,23-34. https://doi.org/10.1016/j.pepi.2017.01.005

Slack, G. A. (1965). Thermal Conductivity of Elements with Complex Lattices:

luppercase $\{\mathrm{B}\}$, luppercase $\{\mathrm{P}\}$, luppercase $\{\mathrm{S}\}$. Phys. Rev., 139(2A), A507--A515.

https://doi.org/10.1103/PhysRev.139.A507

Smith, C. S., \& Palmer, E. W. (1935). Thermal and electrical conductivities of copper alloys. Transactions Of The American Institute Of Mining And Metallurgical Engineers, 117, $225-243$.

Smith, D. E., Zuber, M. T., Phillips, R. J., Solomon, S. C., Hauck, S. A., Lemoine, F. G., ... Taylor, A. H. (2012). Gravity Field and Internal Structure of Mercury from MESSENGER. Science, 336(6078), 214-217. https://doi.org/10.1126/science.1218809

Stanley, S., Bloxham, J., Hutchison, W. E., \& Zuber, M. T. (2005). Thin shell dynamo models consistent with Mercury's weak observed magnetic field. Earth and Planetary Science Letters, 234(1-2), 27-38. https://doi.org/10.1016/j.eps1.2005.02.040

Stevenson, D. J. (1987). Mercury's magnetic field: a thermoelectric dynamo? Earth and Planetary Science Letters, 82(1-2), 114-120. https://doi.org/10.1016/0012821X(87)90111-7

Stevenson, D. J. (2003). Planetary magnetic fields. Earth and Planetary Science Letters, 208, 1-11. https://doi.org/10.1029/GL006i003p00213

Stevenson, David J., Spohn, T., \& Schubert, G. (1983). Magnetism and Thermal Evolution of the Terrestrial Planets. Icarus, 54, 466-489.

Tian, Z., Zuber, M. T., \& Stanley, S. (2015). Magnetic field modeling for Mercury using dynamo models with a stable layer and laterally variable heat flux. Icarus, 260, 263268. https://doi.org/10.1016/j.icarus.2015.07.019 
Tosi, N., Grott, M., Plesa, A. C., \& Breuer, D. (2013). Thermochemical evolution of Mercury's interior. Journal of Geophysical Research E: Planets, 118(12), 2474-2487. https://doi.org/10.1002/jgre.20168

Urakawa, S., Someya, K., Terasaki, H., Katsura, T., Yokoshi, S., Funakoshi, K. ichi, ... Irifune, T. (2004). Phase relationships and equations of state for $\mathrm{FeS}$ at high pressures temperatures and implications for the internal structure of Mars. Physics of the Earth and Planetary Interiors, 143(1-2), 469-479. https://doi.org/10.1016/j.pepi.2003.12.015

Veasey, M., \& Dumberry, M. (2011). The influence of Mercury’s inner core on its physical libration. Icarus, 214, 265-274. https://doi.org/10.1016/j.icarus.2011.04.025

Wang, Y., Uchida, T., Von Dreele, R., Rivers, M. L., Nishiyama, N., Funakoshi, K. I., ... Kaneko, H. (2004). A new technique for angle-dispersive powder diffraction using an energy-dispersive setup and synchrotron radiation. Journal of Applied Crystallography, 37(6), 947-956. https://doi.org/10.1107/S0021889804022502

Wicht, J., Mandea, M., Takahashi, F., Christensen, U. R., Matsushima, M., \& Langlais, B. (2007). The origin of Mercury's internal magnetic field. Space Science Reviews, 132(24), 261-290. https://doi.org/10.1007/s11214-007-9280-5 


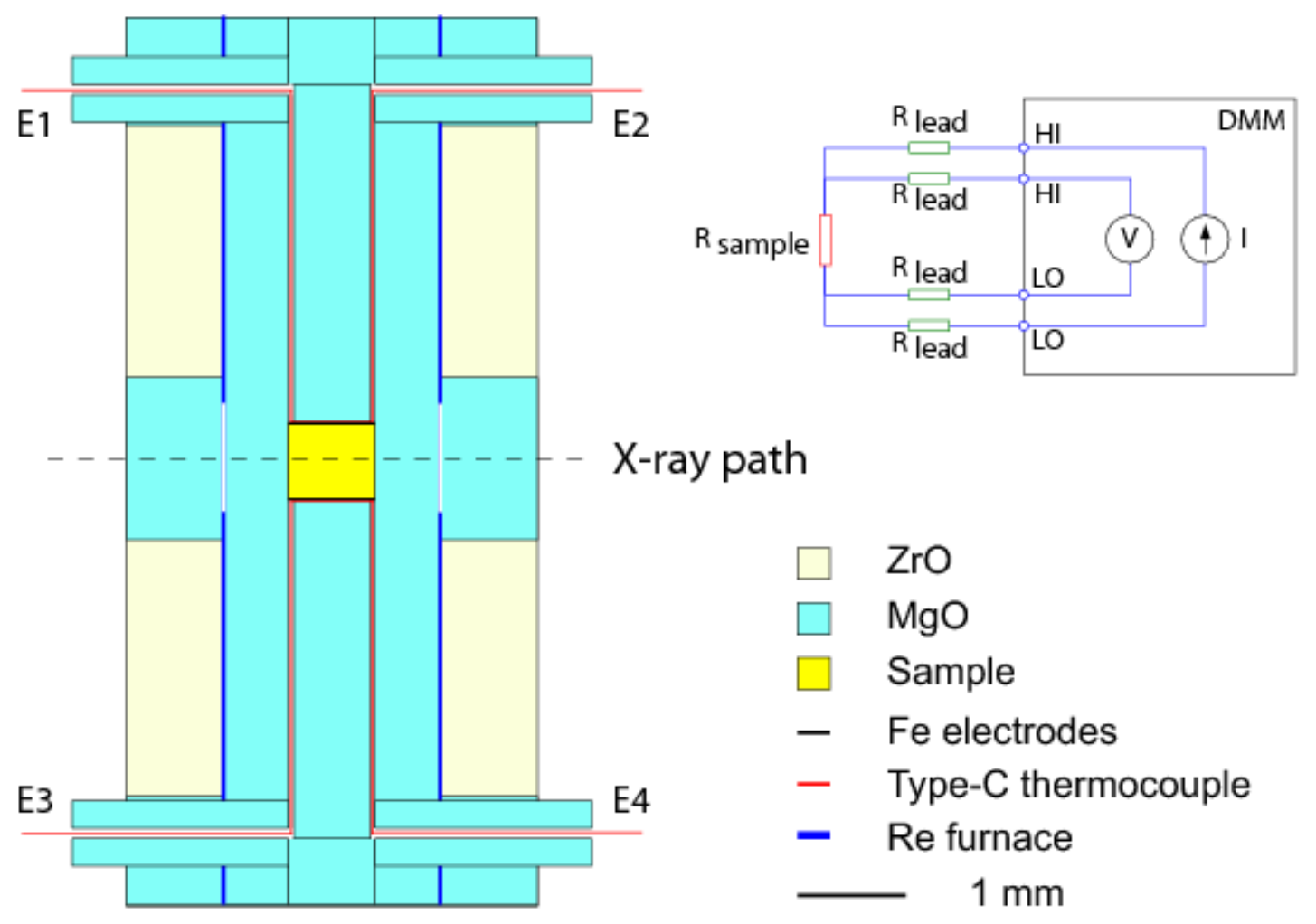

Fig. 1. Schematic cross section of the multi-anvil assembly. The two sets of thermocouples placed top and bottom of the sample serves as electrodes for electrical conductivity measurements. Inset, a schematic diagram showing the electrode connections for the Kelvin (4-wire) resistance measurement technique. 
(K)

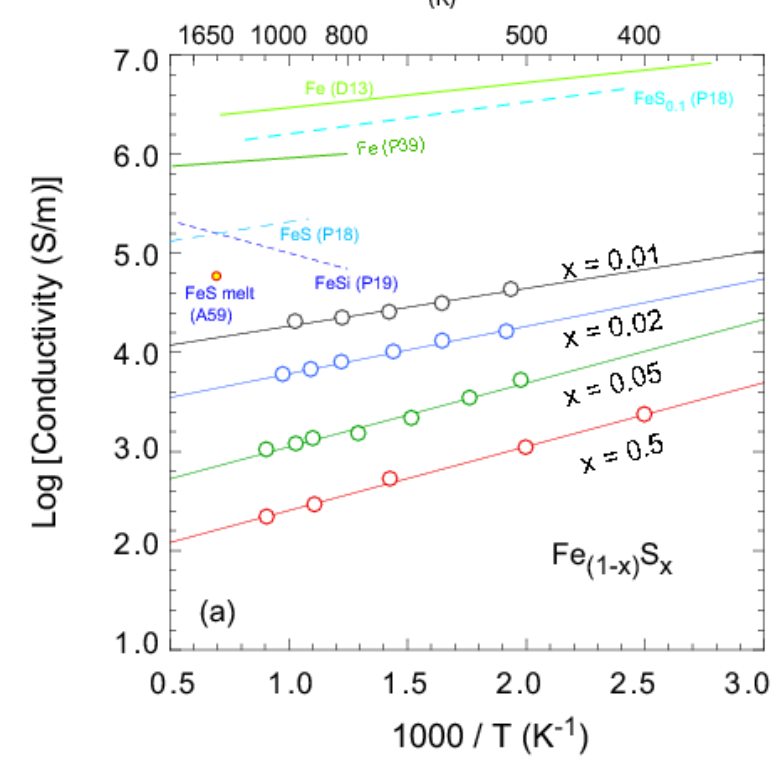

(K)

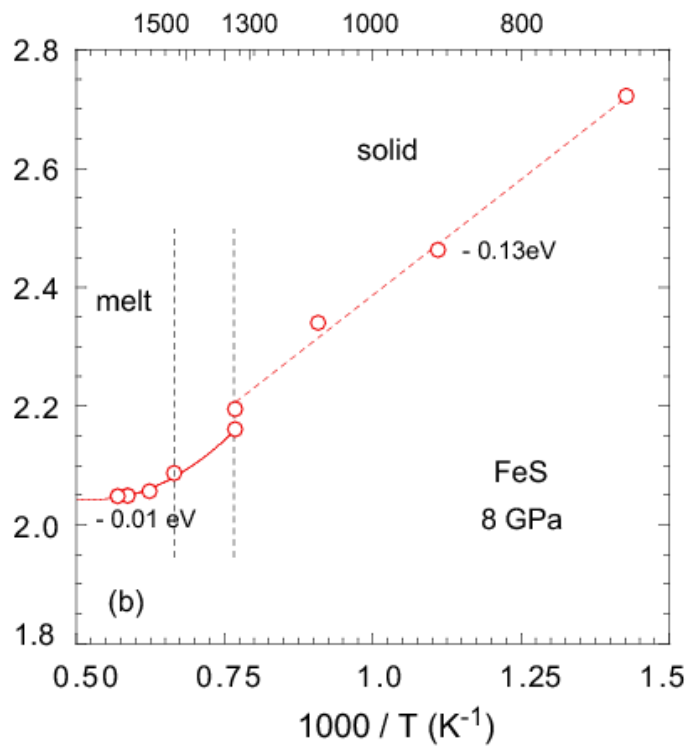

Fig. 2. Electrical conductivity of Fe-S compounds. (a) As a function of reciprocal temperature for various sulfur contents. Note that the compositions are shown next to the fitting lines. Previous works on electrical conductivity of iron alloys are shown for comparison: A59 (Argyriades, Derge, \& Pound, 1959); D13 (Deng et al., 2013); P18 (Pommier, 2018); P19 (Pommier et al., 2019) (b) Electrical conductivity before and after melting of FeS. The activation enthalpy changes with melting and the electrical conductivity of molten FeS depends weakly on temperature. 


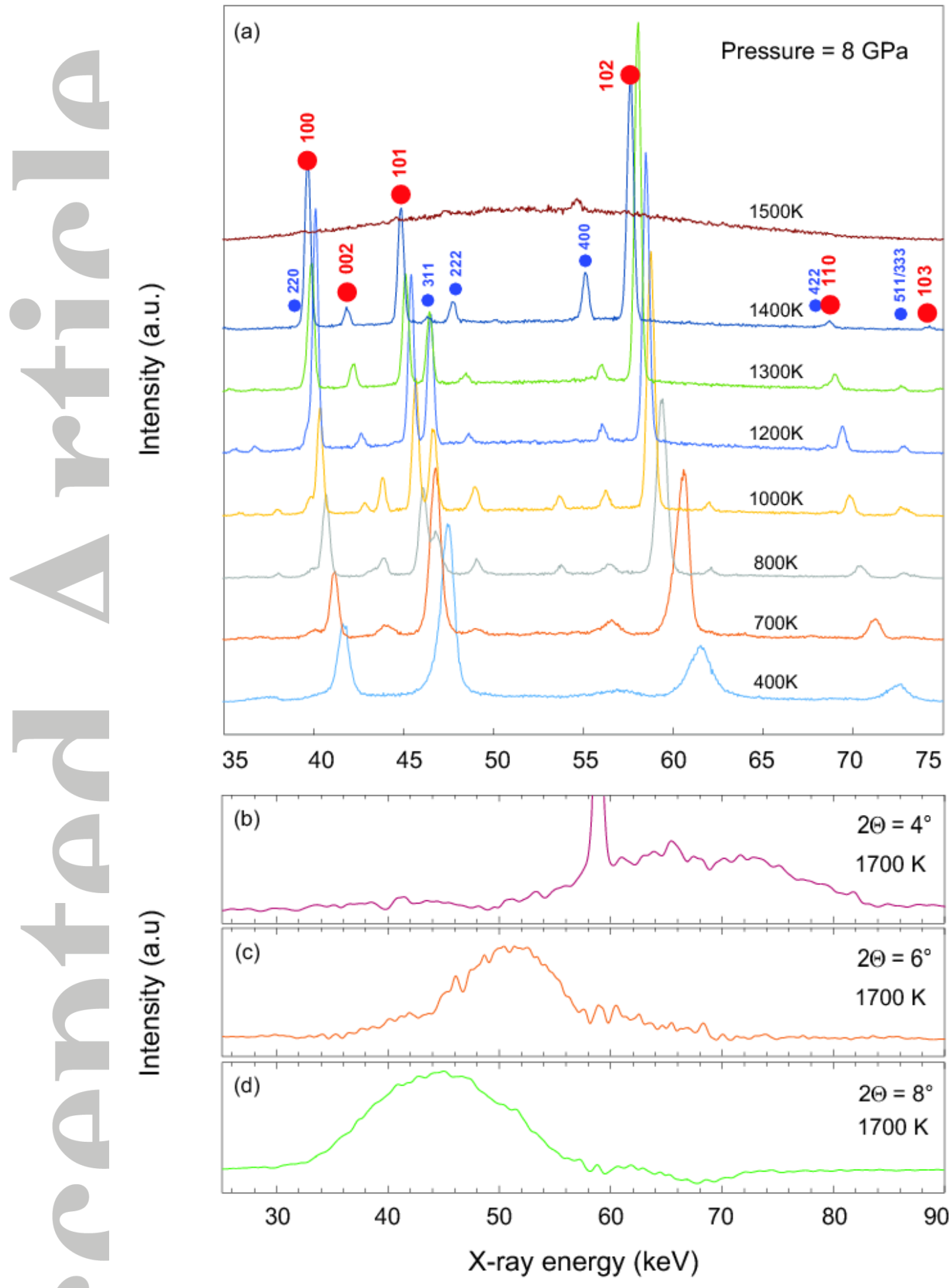

Fig. 3. X-ray diffraction patterns of FeS recorded at high temperature. (a) Evolution with increasing temperature of the diffraction pattern for the run performed at $\sim 8 \mathrm{GPa}$. Red and blue dots correspond to diffraction peaks indexed based on $\mathrm{FeS}-\mathrm{V}$ and $\mathrm{Fe}_{3} \mathrm{O}_{4}$ magnetite, respectively. The ratio of diffraction peak intensities (following the Rietveld approach) 
suggests presence of magnetite in the sample, which $\mathrm{Fe}_{3} \mathrm{O}_{4}$ could come from the unavoidable oxidation of FeS starting material. The general drift of diffraction peaks toward low energies is due to thermal expansion. Diffraction peaks get thinner at high temperatures due to the release of deviatoric stresses built upon compression at $300 \mathrm{~K}$. The melting of the sample occurs between 1400 and $1500 \mathrm{~K} .(\mathrm{b}, \mathrm{c}, \mathrm{d})$ At $1700 \mathrm{~K}$ after melting of FeS at two-theta diffraction angles of 4, 6 and 8 degrees respectively.

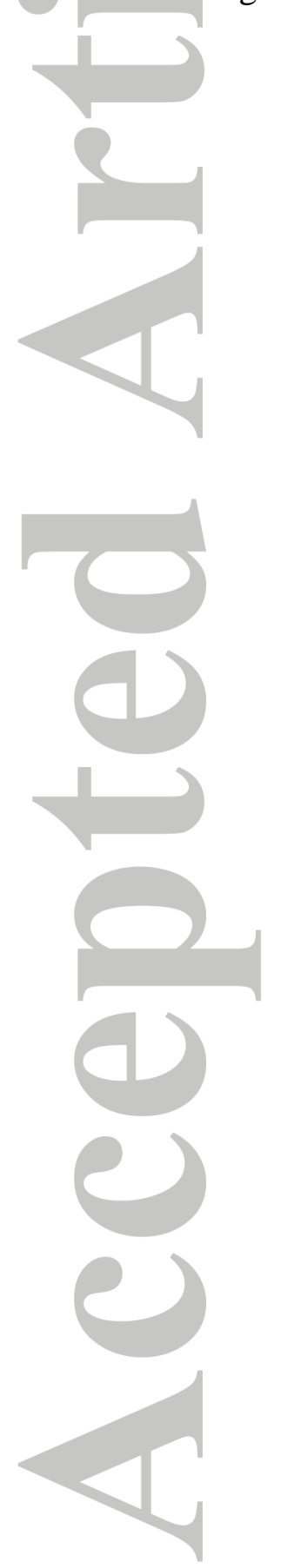




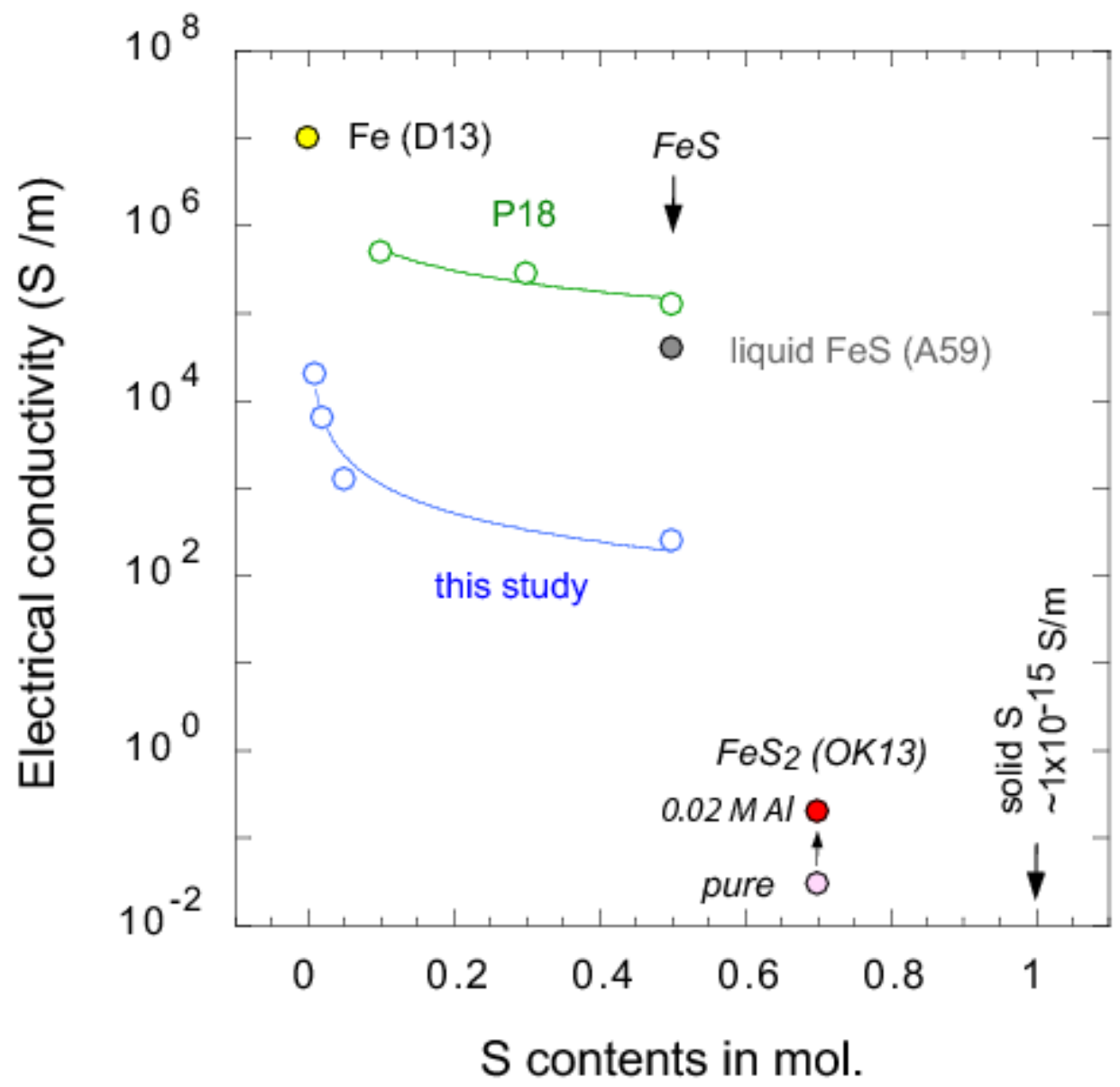

Fig.4. Electrical conductivity as a function of sulfur content in Fe-S alloys. Electrical conductivity decreases with increasing sulfur contents. Previous electrical conductivity data of Fe-S alloys and Fe are shown for comparison. P18 (Pommier, 2018), A59 (Argyriades et al., 1959), D13 (Deng et al., 2013) and OK13 (Osuwa \& Nwaokeorie, 2014). 

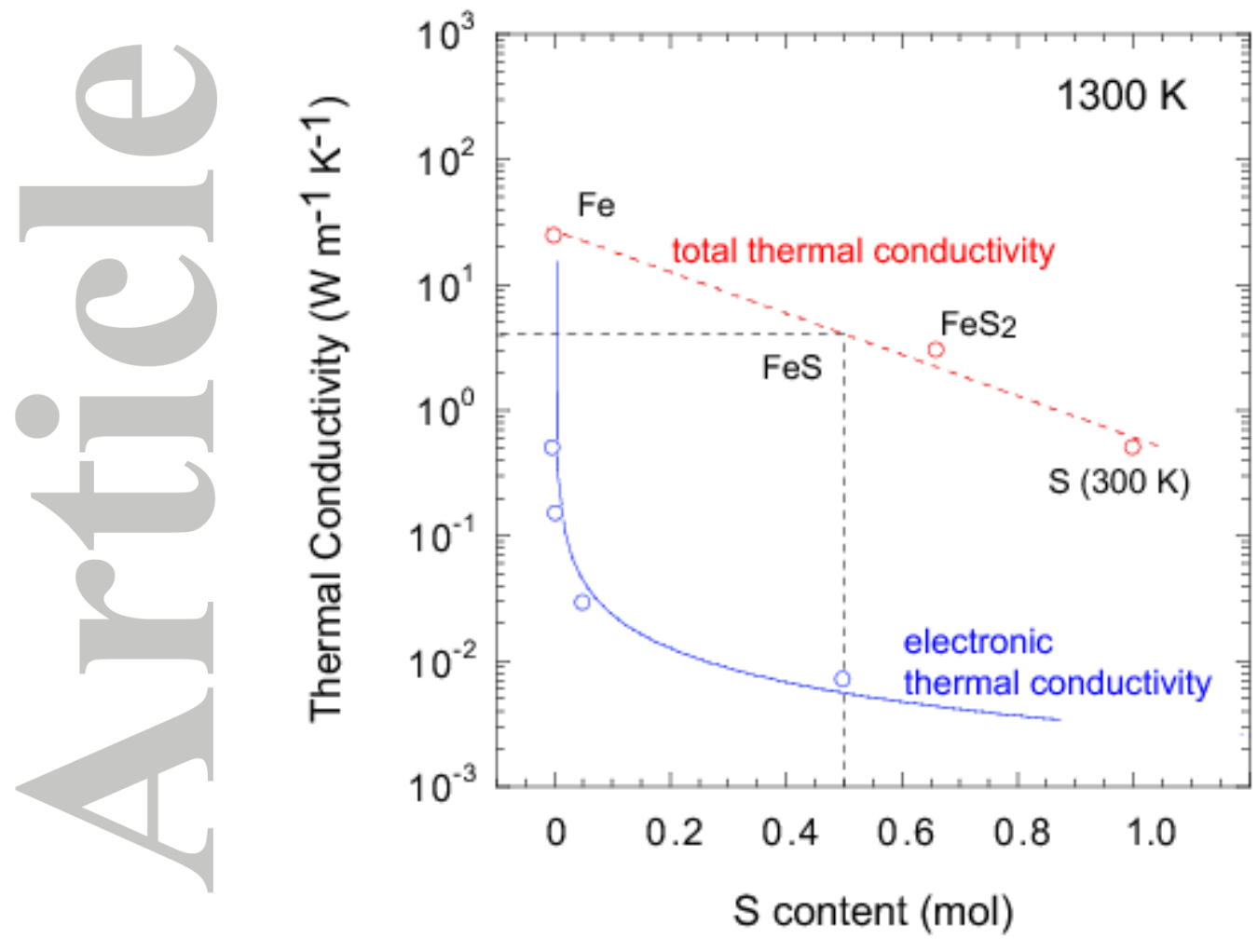

Fig. 5. Thermal conductivity of Fe-S compounds. The electronic thermal conductivity estimated based on the Sommerfeld derivation of the Wiedemann-Franz law for our Fe-S compositions are shown in blue circles. The total thermal conductivity (electronic + phonon) of $\mathrm{Fe}, \mathrm{FeS}_{2}$ and $\mathrm{S}$ are shown in red circles. The thermal conductivity of FeS was estimated to be $\sim 4 \mathrm{Wm}^{-1} \mathrm{~K}^{-1}$ at $1000 \mathrm{~K}$. 

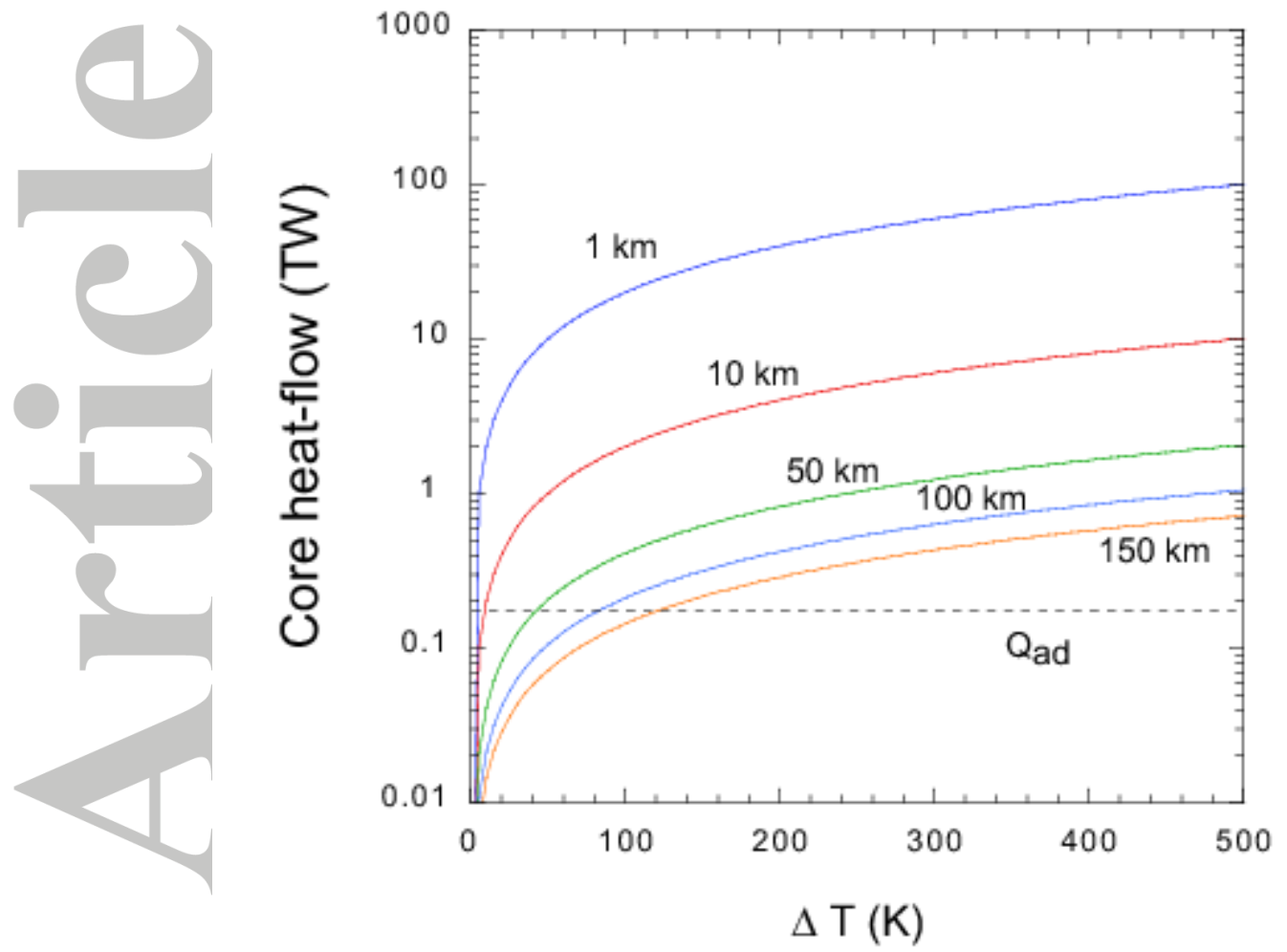

Fig. 6. Mercury's core-mantle boundary heat flow. The calculations are based on an average total thermal conductivity (electron + phonon) of $4 \mathrm{Wm}^{-1} \mathrm{~K}^{-1}$ for $\mathrm{FeS}$ for diverse thermal boundary layer thicknesses as a function of the temperature contrast across the TBL. The adiabatic heat flow $\left(Q_{a d}=4 \pi R_{c}^{2} k_{t o t} \alpha_{c} g_{c} T d C p\right)$ is represented with a black horizontal dashed line (considering $R_{c}=2000 \mathrm{~km}, \alpha_{c}=7 \mathrm{E}-5 \mathrm{~K}^{-1}, g_{c}=4 \mathrm{~m} \mathrm{~s}^{-2}, T_{c}=1800 \mathrm{~K}$ and $C p=850 \mathrm{Jkg}^{-}$ $\left.{ }^{1} \mathrm{~K}^{-1}\right)$ 
(a) early stage

magma ocean

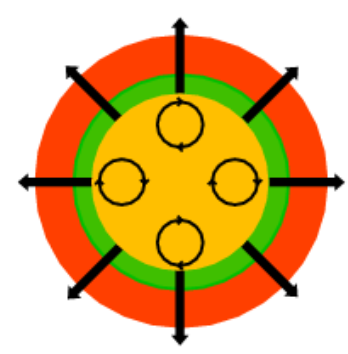

-large heat flux -thermally driven dynamo (b) intermediate stage

solid silicate mantle solidification of the inner core crystallization of FeS

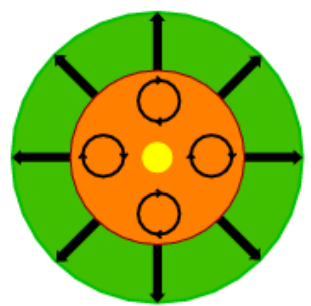

-intermediate heat flux -thermally driven dynamo (c) present stage

\section{solid silicate mantle}

+ solid FeS layer

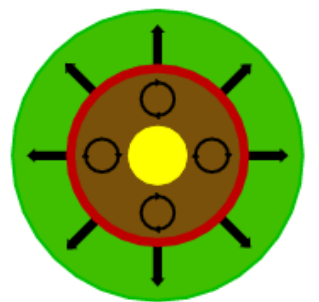

-low heat flux

-thermally and chemically driven dynamo

Fig. 7. Schematic diagram illustrating the evolution of Mercury's dynamo. The thermo-

chemical evolution of Mercury's interior coupled with core-mantle dynamics. The early stages of Mercury core evolution $(\mathrm{a}, \mathrm{b})$ indicate largely a thermally driven dynamo in Mercury due to high heat flux from the core. The present Mercury should have a low heat flux due to the presence of FeS layer at the core-mantle boundary and the dynamo may be powered by both chemical and thermal driven processes. 